\title{
Transcription factors JunB and c-Jun are selectively up-regulated and functionally implicated in fibrosarcoma development
}

\author{
Ella Bossy-Wetzel, ${ }^{1}$ Rodrigo Bravo, ${ }^{2}$ and Douglas Hanahan ${ }^{1}$ \\ ${ }^{1}$ Department of Biochemistry and Biophysics, Hormone Research Institute, University of California, San Francisco, \\ California 94143-0534 USA; ${ }^{2}$ Department of Molecular Biology, Bristol-Myers Squibb Institute for Pharmaceutical Research, \\ Princeton, New Jersey 08543-4000 USA
}

\begin{abstract}
Bovine papillomavirus transgenic mice develop skin tumors arising from dermal fibroblasts in a process comprised of three distinctive stages: mild and aggressive fibromatoses, and fibrosarcoma. In both tissue biopsies and derivative cell lines, the proto-oncogenes $j u n B$ and c-jun are induced in the latter two stages, in contrast to junD and fos. Fibrosarcoma cell lines have increased AP-1 DNA-binding activity. Overexpression of junB or c-jun by transfection into the mild fibromatosis stage elicited changes in cell shape and anchorage independence, whereas junD did not. Similar transfections of normal skin fibroblasts had no effect. Thus, jun $B$ and c-jun represent progression factors whose activities are necessary at an intermediate stage of tumor development, subsequent to the initiation of aberrant proliferation.
\end{abstract}

[Key Words: Tumor progression factors; junB and c-jun; AP-1 transcription complex fibrosarcoma; proto-oncogenes; bovine papillomavirus transgenic mice]

Received August 11, 1992; revised version accepted September 30, 1992.

Numerous studies have provided evidence that multiple genetic or epigenetic alterations occur during neoplastic transformation (for review, see Fearon and Vogelstein 1990; Aaronson 1991; Bishop 1991; Solomon et al. 1991; Weinberg 1991). In one transgenic mouse model of this process, mice harboring the bovine papillomavirus type 1 (BPV-1) genome develop dermal fibrosarcomas in a pathway comprised of at least three stages (Lacey et al. 1986). Initially, two histological grades of hyperplasia arise: mild fibromatosis and aggressive fibromatosis. They differ by the increased density of dermal fibroblasts and overall thickness of the dermal layer in the aggressive condition. Subsequently, dermal fibrosarcomas develop, with a lower frequency than fibromatosis lesions. Tumors frequently arise out of areas of abnormal skin, and fibromatosis tissue can be visualized adjacent to the distinctive fibrosarcoma cells, suggesting that the fibromatoses are progenitors to the fibrosarcomas. All three pathological stages contain extrachromosomal BPV-1 DNA and express viral RNA. Notably, the aggressive fibromatosis cannot be distinguished from the fibrosarcomas by the levels of BPV-1 transcripts and oncogene products (Sippola-Thiele et al. 1989). Thus, the BPV-1 transgene seems insufficient to induce the complete fibrosarcoma phenotype, implicating additional cellular changes in neoplastic conversion of hyperplastic skin lesions into fibrosarcomas.

Cell cultures have been established from each skin pathology and found to represent in vitro many of the characteristics evident in the lesion from which they were derived (Sippola-Thiele et al. 1989). A cytogenetic analysis revealed two types of karyotypic defects in fibrosarcoma but not fibromatosis cells: Chromosome 14 is monosomic or involved in translocations (in $60 \%$ of fibrosarcomas), and/or chromosome 8 is trisomic or partially duplicated (in $70 \%$ of fibrosarcomas) (Lindgren et al. 1989|. These observations imply a recessive locus on mouse chromosome 14, and genes with dominant properties on mouse chromosome 8 . The commonly duplicated region among fibrosarcomas is the $\mathrm{C}$ region of chromosome 8 , wherein two proto-oncogenes, jun $B$ and junD, are localized (Lindgren et al. 1989; Mattei et al. 1990). junB and junD belong to a family of transcription factors that regulate the expression of genes containing the sequence TGACTCA in their promoters (Ryder and Nathans 1988; Ryder et al. 1988, 1989; Ryseck et al. 1988, 1991; Hirai et al. 1989). The third member of the jun family, c-jun, is localized on chromosome 4 (Mattei et al. 1990). Although the three cellular jun genes share extensive sequence homology, they have distinct tissuespecific expression patterns (Wilkinson et al. 1989). c-jun is the cellular homolog of a viral oncogene ( $\mathrm{v}$-jun) carried by an avian sarcoma retrovinus (ASV17) that induces fibrosarcomas in chickens (Maki et al. 1987; Bohmann and Tjian 1989|. v-jun can transform chick embryo fibroblasts, myoblasts, and neuroretinal cells in vitro (Bos et al. 1990; Garcia and Samarut 1990). Notably, v-jun elicits fibrosarcomas and rhabdomyosarcomas in transgenic 
mice in a process that requires initial wounding (Schuh et al. 1990). Both the chromosome 8 duplication and the fibrosarcoma specificity of v-jun motivated the evaluation of a possible involvement of jun genes in dermal fibrosarcoma development of BPV-1 transgenic mice.

\section{Results}

Expression of JunB, c-Jun, and JunD proteins in the stages of fibrosarcoma development

Immunohistochemistry was performed to evaluate the levels of JunB, c-Jun, and JunD proteins in transgenic mouse skin at different steps of tumorigenesis and to investigate the possibility of alterations in the expression pattern of these proteins during the process of tumor development. Tissue from mice of two independent BPV transgenic lines (BPV1.69 and BPV.69rI) was analyzed. An immunohistochemical analysis for the JunB, c-Jun, and JunD proteins in the various stages of this pathway is presented in Figure 1. All three Jun proteins show predominant nuclear localization, as is characteristic for them. In normal skin, JunB is found abundantly expressed in the epidermis, whereas it is either undetectable or present at very low levels in the dermis (Fig. la). The pattern of JunB expression in mild fibromatosis tissue was very similar to that of normal skin tissue (Fig. lb). In marked contrast, JunB was readily detectable in a majority of dermal fibroblasts of aggressive fibromatosis tissue (Fig. 1c). A further increase of JunB protein was seen in fibrosarcoma tissue, where it was detected at high levels in virtually all of the more densely packed fibrosarcoma cells (Fig. 1d). The expression pattern for c-Jun during the stages of tumorigenesis was similar to JunB. c-Jun was expressed at very low levels in dermal fibroblasts of normal skin and mild fibromatosis (Fig. $\mathrm{le}, \mathrm{f}$ ) and was clearly present at higher levels in both aggressive fibromatosis and fibrosarcoma tissue (Fig. $1 \mathrm{~g}, \mathrm{~h}$ ). In contrast, JunD was found at abundant levels in both dermal and epidermal layers of normal skin and mild fibromatosis (Fig. li,j). There was no indication of any increased JunD expression in aggressive fibromatosis and fibrosarcoma tissue (Fig. 1k,1). Because all three Jun proteins are known to form heterodimers with c-Fos and related proteins to generate the AP- 1 transcription factor complex (Cohen and Curran 1988; Halazonetis et al. 1988; Zerial et al. 1989), the levels of the Fos proteins were also examined. In all stages, Fos was present in dermal fibroblasts at clearly detectable and similar levels (data not shown). Moreover, we analyzed expression of the proto-oncogene myc by immunostaining tissue sections from these four stages. Similar to the observations with JunD and Fos, Myc protein was detectable but the levels did not differ appreciably in any of the four skin conditions (data not shown). The results indicate that JunB and c-Jun are specifically up-regulated in the advanced fibromatosis and fibrosarcoma stages, whereas JunD and Fos (and $\mathrm{Myc}$ ) proteins are expressed at similar levels throughout tumorigenesis.
Increase of JunB and c-Jun proteins in aggressive fibromatosis and fibrosarcoma cell lines

The cultured cells representative of normal dermal fibroblasts and the three abnormal conditions were used to further characterize the observed up-regulation of c-Jun and JunB. Nuclear extracts from low-passage fibroblast cultures representing the various conditions of skin tumorigenesis were examined by Western blot analysis (Fig. 2). JunB protein was expressed at very low (and sometimes undetectable) levels in normal fibroblasts and mild fibromatosis cultures (Fig. 2A, lanes N,MF). Similarly, c-Jun protein was undetectable in normal fibroblasts and mild fibromatosis cultures (Fig. 2B, lanes $\mathrm{N}, \mathrm{MF}$ ). However, both proteins could be readily detected in aggressive fibromatosis nuclear extracts (Fig. 2A and $B$, lanes $A F)$. JunB and c-Jun levels were increased even further in fibrosarcoma nuclear extracts (Fig. 2A and B, lanes FS). In contrast, JunD protein was clearly present in all four cell types. JunD protein appeared to be decreased in fibrosarcoma nuclear extracts relative to normal fibroblasts and the two earlier stages of tumor development (Fig. 2C). Finally, analysis of Fos showed it to be expressed at comparable levels in all four stages (Fig. 2D). Thus, Western blotting analysis of the cell cultures derived from tissue biopsies confirms the increases in JunB and c-Jun in the later stages of fibrosarcoma development originally detected by immunohistochemical analysis of tissue sections.

\section{Fibrosarcoma cell lines contain increased $A P-1$ DNA-binding activity}

To test whether elevated levels of JunB and c-Jun alter a Jun-related function, their DNA-binding ability in nuclear extracts from the distinct cell cultures was quantified in a gel retardation assay. The AP-1 site is a heptameric sequence contained in the regulatory regions of various viral and cellular genes (Garcia-Carranca et al. 1988; Martin et al. 1988; Schönthal et al. 1988) and is specifically recognized by either Jun-Jun homodimers or Jun-Fos heterodimers (Bohmann et al. 1987; Angel et al. 1988; Halazonetis, et al. 1988; Nakabeppu et al. 1988; Rauscher et al. 1988a,b; Hirai, et al. 1989; Ryseck and Bravo 1991). A radiolabeled oligonucleotide probe (33mer) carrying the AP-1 consensus sequence (TGACTCA) was incubated with nuclear extract prepared from a normal skin fibroblast culture, two mild fibromatosis cultures, three aggressive fibromatosis cell lines, and four fibrosarcoma cell lines. Extracts from normal and mild fibromatosis cells display similar, low AP-1 DNA-binding activity (Fig. 3A lanes 1,2). A modest increase in activity was observed in one mild fibromatosis and all three aggressive fibromatosis lines (Fig. 3A, lanes 3-6). In the fibrosarcoma nuclear extracts, an additional enhancement in the AP-1 DNA-binding activity was detected in all four fibrosarcoma lines tested (Fig. 3A, lanes 7-10). The amount of protein-DNA complex was quantified by densitometry of the autoradiogram. The relative increase in specific DNA-binding activity in nuclear ex- 
Bossy-Wetzel et al.

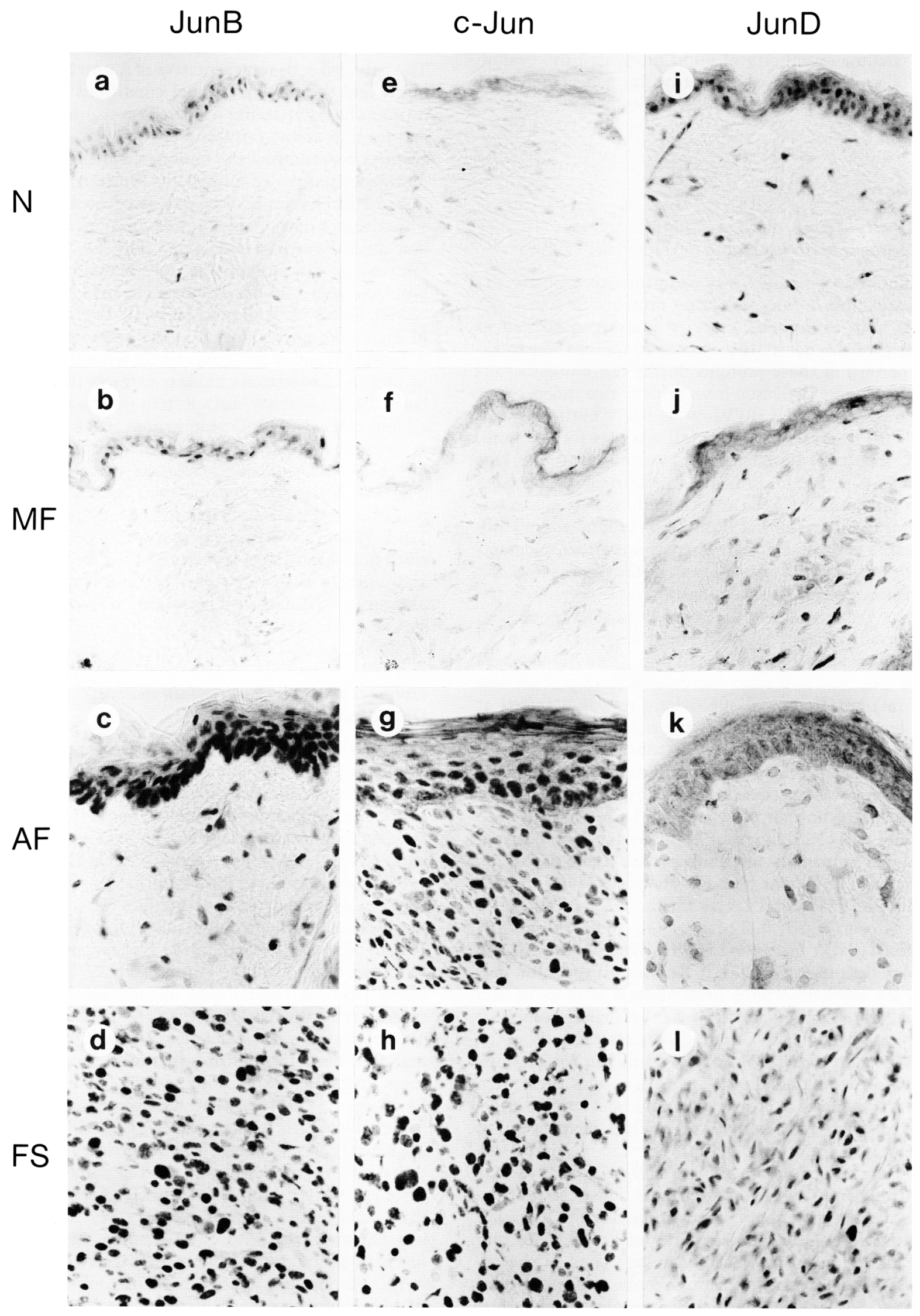

Figure 1. (See facing page for legend.) 
A

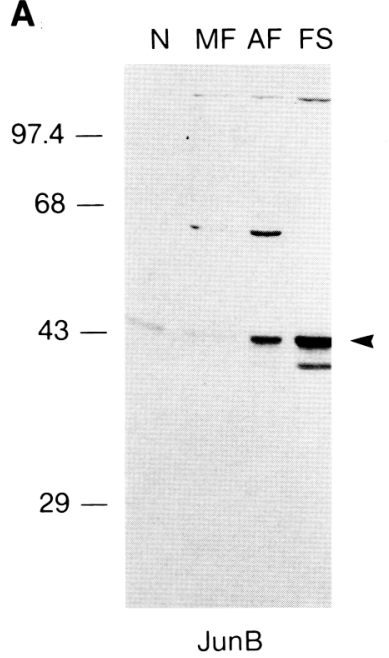

B

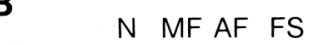

C

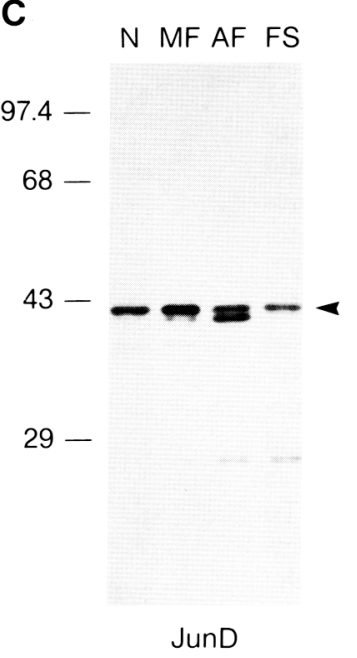

JunD
D

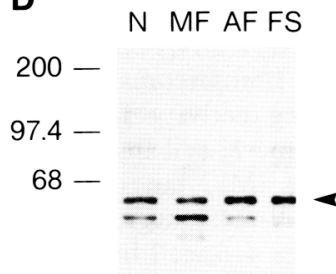

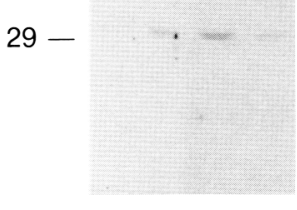

C-Jun

Figure 2. Quantitative analysis of JunB, c-Jun, JunD, and c-Fos proteins in normal fibroblast (N), mild fibromatosis (MF), aggressive fibromatosis $(\mathrm{AF})$, and fibrosarcoma (FS) cell lines by Western blotting. Nuclear extracts from one normal fibroblast (nf) cell line (nf23784), three mild fibromatosis cell lines (MF9268, MF14249, MF14246), three aggressive fibromatosis cell lines; (BPV21, BPV3, BPV7), and five fibrosarcomas (BPV2, BPV11, BPV1, 855, BPV23) were prepared and analyzed. The analysis of nuclear extracts from the four representative cell lines each (nf 23784, MF9268, BPV21, BPV11) is shown. Twenty micrograms of the four nuclear extracts (Piette et al. 1988) was electrophoresed through each lane of four $10 \%$ SDS-polyacrylamide gels and transferred to nitrocellulose. The blots were incubated with anti-JunB $|A|$, anti-c-Jun $(B \mid$, anti-JunD $(C)$, and anti-Fos $(D)$ antibodies. The specific band is indicated by the arrow. In the analysis of c-Jun $(B)$, additional bands are present. These bands are nonspecific and have varied from experiment to experiment. The increase of bona fide c-Jun in fibrosarcoma was confirmed using a second anti-c-Jun-specific rabbit serum. Additional bands were also visible in the analysis of c-Fos $(D)$. In this case, we suspect that the bands represent cross-reactivity to Fos-related polypeptides, because the IgGs were affinity-purified using an amino-terminal c-Fos peptide (see Materials and methods). To confirm that equal amounts of protein were analyzed in each lane, the protein blots were stained with $0.5 \%$ Ponceau S solution, before probing the blot with specific antibodies.

tracts was approximately threefold for aggressive fibromatosis and ninefold for fibrosarcoma, when compared with normal fibroblast.

To verify the specificity of DNA binding, competition experiments were performed with an excess of either an unlabeled mutant AP-1 oligonucleotide (AP-1*) or of the unlabeled oligonucleotide containing the AP-1 consensus sequence (Fig. 3B). In this experiment nuclear extracts from normal fibroblasts and fibrosarcoma cells were analyzed. A 100-fold molar excess of mutant AP-1 * sequence (GAATTCG) could not compete away the binding achieved with the labeled AP-1-specific (TGACTCA) probe. However, unlabeled AP-1-specific oligonucleotide, at the same 100-fold molar excess, completely inhibited binding to the labeled AP-1 site, as evidenced by the absence of labeled protein-DNA complexes.

To investigate whether the enhanced AP-1 DNA-binding activity in fibrosarcomas consists of an increase in Jun-Jun homodimer or Jun-Fos heterodimer formation, nuclear extracts from an aggressive fibromatosis and one fibrosarcoma cell line were preincubated with increasing amounts of anti-Fos antibodies. As shown in Figure 3C,

Figure 1. Immunohistochemical analysis of JunB, c-Jun, and JunD in normal skin (N), mild fibromatosis (MF), aggressive fibromatosis $(\mathrm{AF})$ and dermal fibrosarcomas (FS) of BPV-1 transgenic mice. Tissue sections were immunostained with rabbit antisera specific for JunB, c-Jun, and JunD and visualized by incubation with HRP-conjugated secondary antibodies. Jun-positive cells show black nuclear staining. JunB-expressing cells are localized in normal and mild fibromatosis in the epidermis $(a, b)$. In contrast, an increase in JunB protein is evident in hyperplastic dermis of agressive fibromatosis and in fibrosarcoma tissue $(c, d)$. Similarly, c-Jun is present at very low abundance in the dermis of normal and mild fibromatosis $\langle e, f\rangle$. A significant increase occurs in agressive fibromatosis and fibrosarcoma tissue $(g, h)$. JunD-positive cells are detectable in abundant amounts throughout all four stages of fibrosarcoma development $\{i, j, h, l\}$. An enlargement of the nuclei was noted in tissues of the agressive fibromatosis and fibrosarcoma stages, which may be a result of the more aneuploid character of these cells. The epidermal layer in aggressive fibromatosis lesions is enlarged and shows a significant increase in JunB and c-Jun. As described earlier, some of the lesions in BPV-1 mice have an atypical epidermis, which does not progress to neoplasia and is inferred to be reactive to the dermal proliferation (Lacey et al. 1986). Secondary antibody controls indicate that the cytoplasmic staining is nonspecific. Normal skin tissue from two transgenic mice (mouse 26058 and 20702 ); mild fibromatosis tissue from two transgenic mice (mouse 22591 and 24875), aggressive fibromatosis tissue from two mice (mouse nos. 26058 and 26717), and fibrosarcomas from four transgenic mice (mouse 26058, 24876, 20701, and 24873) have been analyzed and representative tissue sections are shown. The magnification of each photograph is $141 \times$. 
Figure 3. AP-1 DNA-binding activity is elevated in fibrosarcomas. (A) The AP-1 DNA-binding activity in normal fibroblasts ( $N$, lane 1 ; cell line nf23784), mild fibromatosis (MF, lanes 2,3; cell lines MF9268, MF14249), aggressive fibromatosis (AF, lanes 4-6; cell lines BPV3, BPV7, BPV21), and fibrosarcomas (FS, lanes 7-10; cell lines BPV11, 855, BPV1, BPV23) was quantified by gel-retardation analysis. $\mathrm{Nu}$ clear extracts were prepared by the method of Andrews and Faller (1991) and the gel retardation assay was performed as described in Materials and methods. $(B)$ To test the specificity of the retarded complex, a 100-fold molar excess of either the unlabeled mutant AP-1 ${ }^{*}$ or AP-1-specific oligonucleotide was added to the reaction. (C) The AP-1-specific complex contains Fos. Nuclear extracts from either aggressive fibromatosis (AF) or fibrosarcoma (FS) were investigated for the presence of Jun/ Fos heterodimers by using Fos-specific antibodies to supershift the DNA protein complex. The extracts were preincubated with either no $(-)$ or increasing amounts of Fos-specific $\operatorname{IgG}(1,5,8 \mu \mathrm{g} /$ reaction $)$ for $1 \mathrm{hr}$ on ice, and the gel retardation assay was then performed, as described in Materials and methods. $(D)$ The AP-1-specific complex contains Jun. The extracts from an aggressive fibromatosis and a fibrosarcoma were preincubated with either no $(-)$ or increasing amounts of pan-specific Jun antibodies $(0.1 \mu l$ or $1 \mu l /$ reaction $)$, and a gel-retardation assay was performed.
A

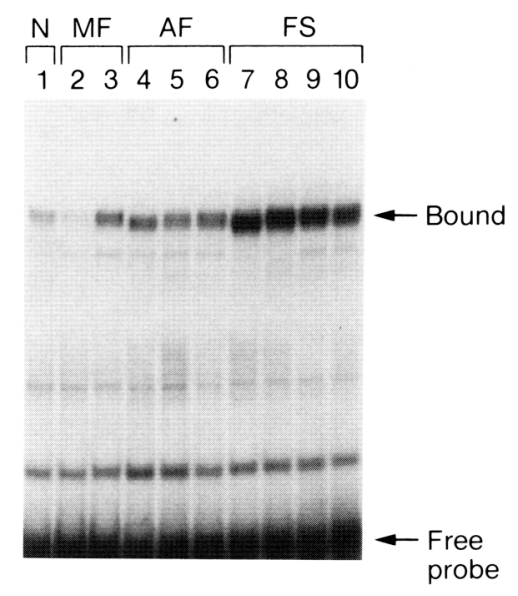

C

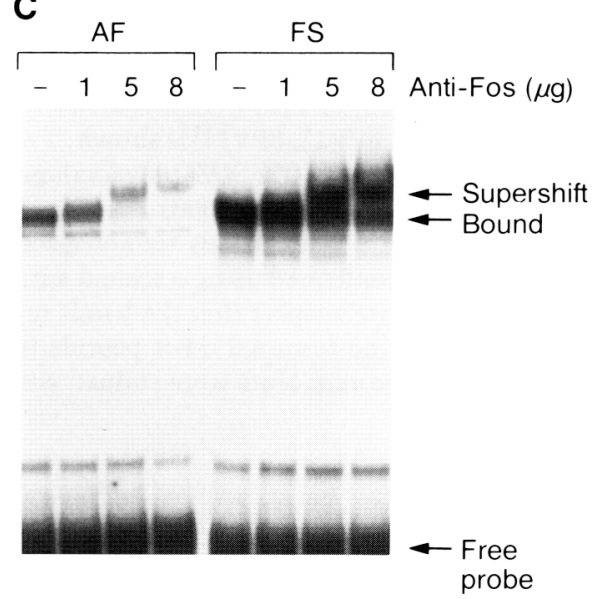

B
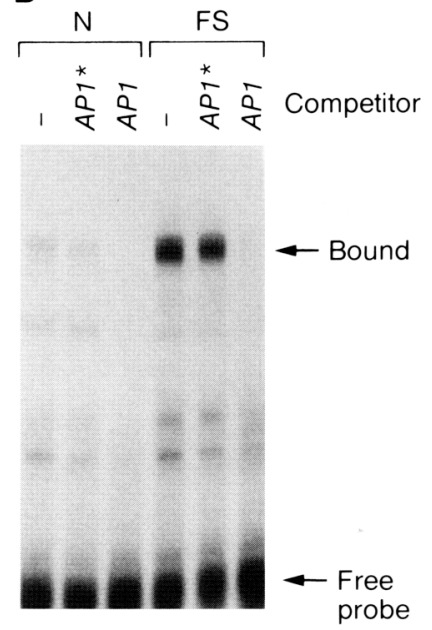

D

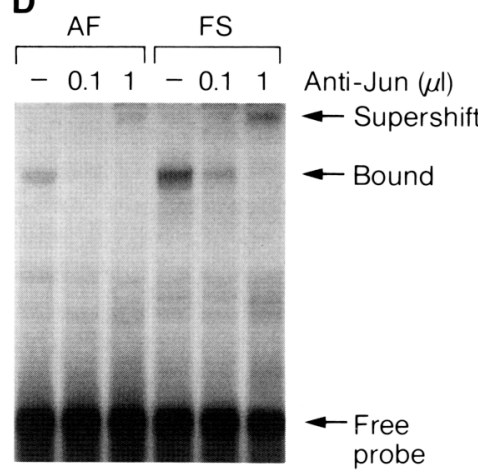

the anti-Fos IgG produced a supershift when added to the reaction, thus indicating that Jun-Fos heterodimers are present in the complex. Similar experiments with an anti-Jun family-specific antibody resulted in a complete shift of the AP-1 activity using nuclear extracts from an aggressive fibromatosis and a fibrosarcoma line (Fig. 3D). This complete supershift is in contrast to that seen with anti-Fos antibodies, wherein not all of the DNA-binding activity could be converted into a supershift band in fibrosarcoma nuclear extract. The difference in the supershifts suggests that the increased levels of Jun-B and c-Jun in fibrosarcomas result in the formation of appreciable amounts of Jun-Jun dimers in addition to Jun-Fos heterodimers.

\section{Up-regulation of JunB, c-Jun, and JunD in the early stages of tumorigenesis}

To assess whether the selective increases in JunB and c-Jun levels have functional roles in this tumorigenesis pathway, the cDNAs of jun $B$, c-jun, and junD were placed under the control of the Moloney murine sarcoma virus-long terminal repeat (MSV-LTR) and transfected into mild fibromatosis cells (line MF 14249). The vector containing the neomycin-resistance gene was transfected as a control. After 2 weeks, 30 G418-resistant colonies were isolated for each construct and expanded into cell lines. In an initial study nuclear extracts from 10 randomly selected lines of each transfection were analyzed by Western blotting for expression of the product of the transfected jun gene. The protein level varied greatly among the independently isolated colonies (data not shown). Three cell lines with the clearest increase in protein levels were selected from each jun transfection for subsequent studies. The evaluation of expression in these selected lines is shown in Figure 4. The molecular weights of the endogenous and transfected jun gene products are identical; therefore, the total amount of the respective Jun protein is compared with that in the parental cell line. All three $\mathrm{MF} /$ jun $B$ lines showed an approximately threefold increase in JunB protein when compared with the parental MF cell line (Fig. 4A, lanes 2-4). The analysis of the MF/c-jun lines showed adundant c-Jun $(>10 \times)$, in comparison with both control and nontransfected lines, where c-Jun is virtually undetectable (Fig. 2 and 4B). Similarly, JunD was clearly overex- 


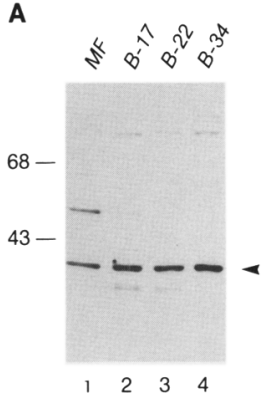

B

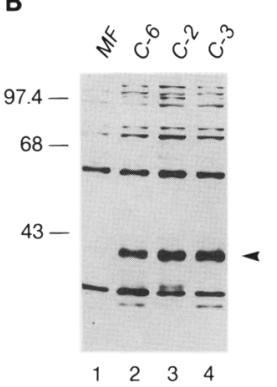

C

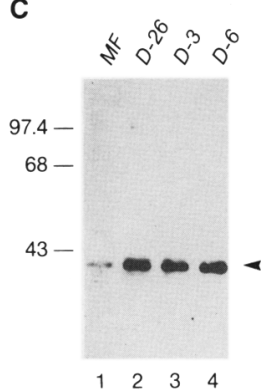

Figure 4. Overexpression of Jun proteins in jun-transfected mild fibromatosis cells. Nuclear extracts were prepared (Andrews and Faller 1991) from untransfected mild fibromatosis cells (MF) and mild fibromatosis cells transfected with jun $B$ (B-17, B-22, B-34), c-jun (C-6, C-2, C-3), and junD (D-26, D-3, D-6). Equal amounts of nuclear extracts $(20 \mu \mathrm{g})$ were separated on $10 \%$ SDS-polyacrylamide gels, transferred to nitrocellulose membrane, and probed with anti-JunB antibodies $(A)$, anti-c-jun antibodies $(B)$, and anti-JunD antibodies $(C)$. The antibody reaction was visualized using the Amersham-ECL system. The Jun proteins are indicated by arrowheads.

pressed in junD transfectants, $\sim 10$-fold over the parental mild fibromatosis line (Fig. 4 C). In the cases of junB and c-jun, the expression of the transfected plus endogenous Jun protein was comparable to the levels found in fibrosarcoma cells (Fig. 2).

junB and $c$-jun induce partial transformation of mild fibromatosis cells

The mild fibromatosis cells transfected with c-jun, junB, or junD were then assessed for changes in cellular phenotype. One evident change was in cell morphology, which was clearly altered in the junB and c-jun transfectants but not in junD or control transfections. The normally large and extended mild fibromatosis cells became more elongated, less contact inhibited, and aligned in parallel arrays (Fig. 5). However, the typical disorganized pattern of spindle-shaped cells that is characteristic of bona fide aggressive fibromatosis and fibrosarcoma cells was not observed in either c-jun- or junB-transfected mild fibromatosis cells (Fig. 5).

The overexpression of JunB and c-Jun not only altered cell shape but also influenced growth rate. One line from each transfection analyzed in Figure 4 was selected for this study. The cell-doubling times in $10 \%$ calf serum were as follows: MF/c-jun (clone C6), $16 \mathrm{hr} ; \mathrm{MF} /$ junB (clone $\mathrm{B} 17$ ), $18 \mathrm{hr}$; and $\mathrm{MF} /$ junD (clone D-6), $24 \mathrm{hr}$. These values can be compared with the parental mild fibromatosis cells ( $24 \mathrm{hr}$ ) with the mild fibromatosis line transfected with a neo vector alone $(30 \mathrm{hr})$, and with a genuine fibrosarcoma (BPV11), $16 \mathrm{hr}$. After 7 days of culture from an initial seeding of $1 \times 10^{4}$ cells $/ 6-\mathrm{cm}$ dish, the saturation density was determined for each representative cell line: mild fibromatosis, $4 \times 10^{5} ; \mathrm{MF} /$ iun $D$, $5 \times 10^{5} ; \mathrm{MF} /$ iun $B, 2 \times 10^{6} ; \mathrm{MF} / \mathrm{c}-$ jun, $4 \times 10^{6}$; and FS BPV11, $4 \times 10^{6}$. Thus, c-jun and jun $B$ transfectants are comparable to fibrosarcoma cells in growth rate and sat-

uration density, whereas jun $D$ and vector alone transfectants are similar to the parental mild fibromatosis cells.

Aggressive fibromatosis and fibrosarcoma cells are able to display anchorage- independent growth and form tumors in nude or syngenic mice (Sippola-Thiele et al. 1989). We therefore tested whether overexpression of a jun gene could allow mild fibromatosis cells to grow in soft agar. In contrast to mild fibromatosis cells transfected with the vector alone or with iunD, colony formation was evident for both c-jun and jun $B$-transfected mild fibromatosis cells (Fig. 6A). The MF/c-jun transfectants were particularly effective at forming colonies. Fourteen percent of the c-jun-transfected mild fibromatosis cells grew in soft agar, which exceeds the $9 \%$ seeding efficiency of fibrosarcoma cells. Aggressive fibromatosis cells were somewhat less effective, giving, on average, $6 \%$ colonies when $10^{5}$ cells were seeded. This efficiency is comparable to $5 \%$ value obtained with the jun $B$-transfected mild fibromatosis cells. It is notable that the MF/c-jun colonies were typically larger in size than the MF/junB colonies (Fig. 6B), suggesting a more rapid growth rate in soft agar as well as on a solid substrate. The differential effects of c-Jun and JunB could be ascribed to the modest 3 -fold increase in JunB levels in the transfectants as compared with the 10 -fold increase in c-Jun (Fig. 4A,B), as well to distinct functional activities of the proteins.

These same cell lines were then injected subcutaneously at three different dosages $\left(2 \times 10^{6}, 1 \times 10^{5}\right.$, $1 \times 10^{4}$ cells) into immunodeficient mice to assess their ability to form tumors. The fibrosarcoma line (BPV11) used as a positive control established visible tumors at all three inoculation levels within 1 week after injection. By 2 weeks, the tumor volume exceeded $300 \mathrm{~mm}^{3}$ from the $2 \times 10^{6}$ cell transplant. In clear contrast, neither the c-jun, jun $B$, nor junD transfectants were tumorigenic by this assay, even after 2 months of incubation. The results suggest that overexpression of junB or c-jun in mild fibromatosis cells can only induce a subset of the transformed characteristics of the aggressive fibromatosis and fibrosarcoma cells.

A similar series of transfection experiments were conducted using normal dermal fibroblasts. Four to six neomycin-resistant clones from each jun transfection of a normal fibroblast culture (nf23784) were selected for analysis. None of the junB-, c-jun-, or junD-transfected normal fibroblast cells showed changes in morphology; none formed colonies in soft agar; and none produced tumors upon subcutaneous injection (data not shown). Thus, the phenotypic changes conferred by up-regulation of JunB and c-Jun were evident only in the mild fibromatoses-stage cells, which express the BPV oncogenes, but not in the normal dermal fibroblast cells from which they arose.

\section{Discussion}

The expression and functional roles of the transcription factors JunB, c-Jun, and JunD during multistep skin tumorigenesis induced by BPV oncogenes has been evalu- 


\section{MF-neo}

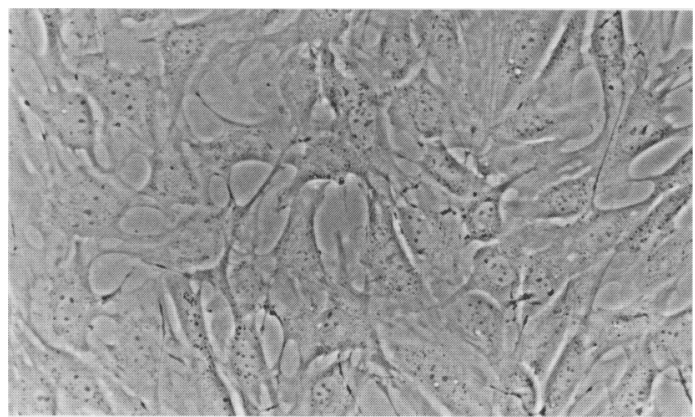

\section{MF-junB}

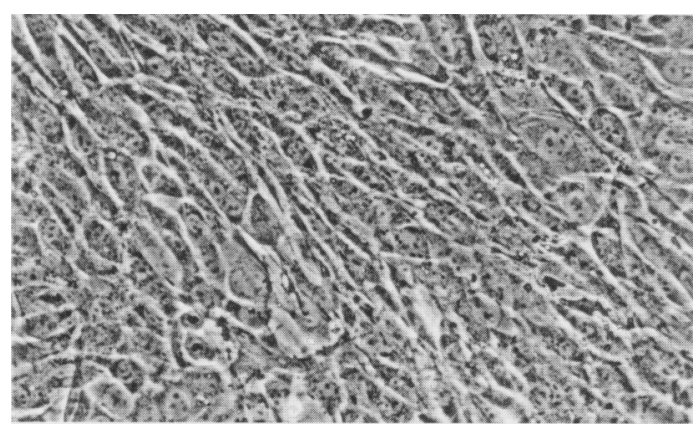

AF

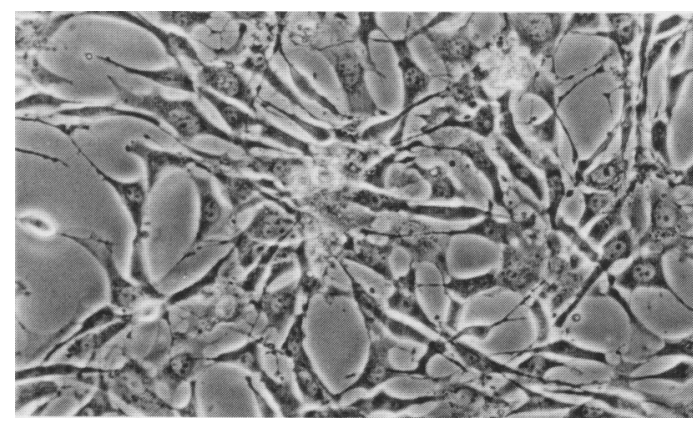

MF-junD

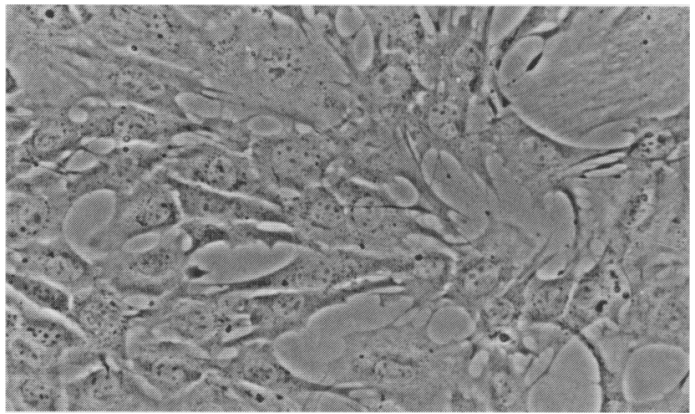

MF-c-jun

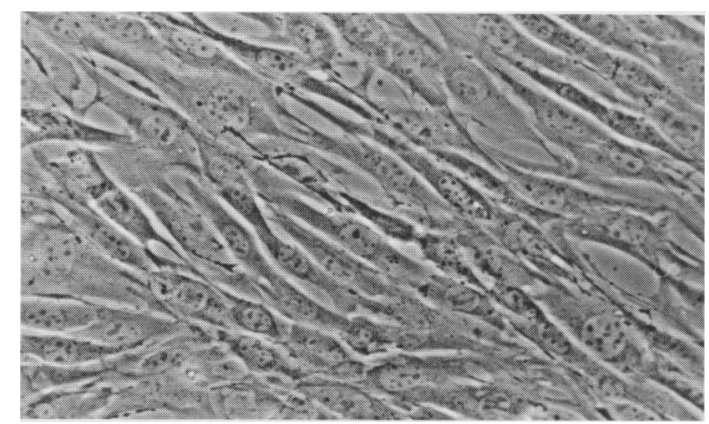

FS

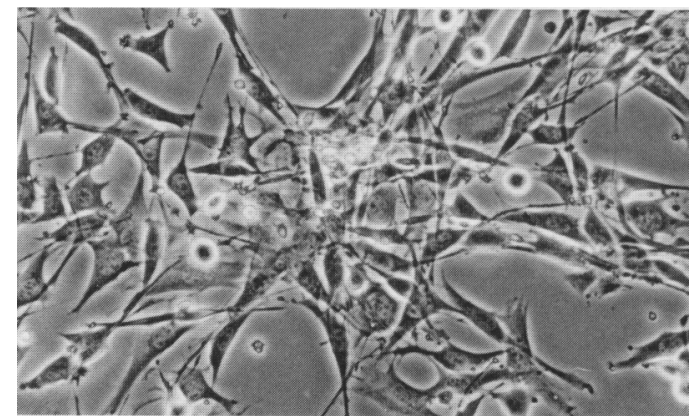

Figure 5. Change in cell morphology induced by the expression of iun genes in mild fibromatosis (MF) cells. Cells were seeded at $1 \times 10^{5}$ cells $/ 100-\mathrm{mm}$ dish in DMEM plus $5 \%$ calf serum and grown for 3 days. Photographs were taken under phase contrast. The magnification of each photograph is $113 \times$.

ated. Immunohistochemical analysis of tissue biopsies representative of the normal condition and the three stages of tumor development revealed a pronounced increase in the JunB and c-Jun products in advanced preneoplastic lesions (aggressive fibromatosis) and in solid tumors (the fibrosarcomas). On the other hand, JunD, Fos, and c-Myc were expressed at similar levels in normal skin and in all skin pathologies. Biochemical analysis of cell cultures derived from the four stages confirmed the up-regulation of JunB and c-Jun. In contrast, JunD levels may actually decrease in the fibrosarcoma cell lines.

The assessment of possible involvement of the jun proto-oncogenes in this tumorigenesis pathway was motivated by the localization of $j u n B$ and $j u n D$ to a region of chromosome 8 that is duplicated in $70 \%$ of the fibrosarcomas (Lindgren et al. 1989). The implication was partially confirmed by the up-regulation of jun $B$. However, c-jun, which is located on chromosome 4 , was also elevated, whereas junD on chromosome 8 was not. Moreover, fibrosarcoma cells lacking chromosome 8 duplications nevertheless evidenced up-regulation of $j u n B$ and c-jun, further strengthening the conclusion that the mechanisms governing this up-regulation are more complex than mere gene duplication. One can speculate that regulatory interactions between c-Jun and JunB (and their genes) may be involved. jun $B$ and c-jun could also be influenced by other events, which include increased expression of the BPV oncogenes (Sippola-Thiele et al. 1989|, and, by consequence, possible activation of the 


\section{B}
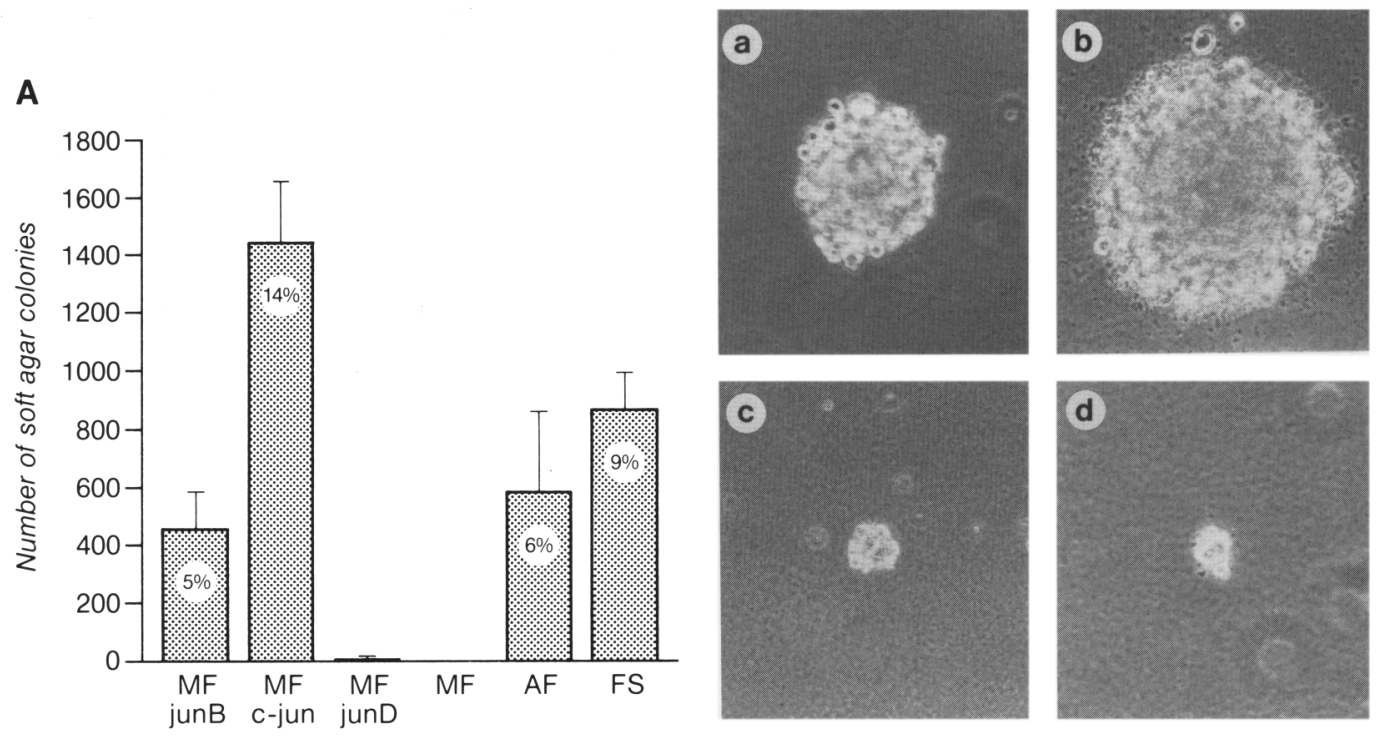

Figure 6. Growth of jun-transfected mild fibromatosis (MF) cells in soft agar. $(A)$ Quantitative analysis of colony formation upon seeding $1 \times 10^{5}$ cells into soft agar in $60-\mathrm{mm}$ dishes, as described in the Materials and methods. After 2-3 weeks of incubation, colonies were stained with MTT and counted. The data represent three independent experiments. $(B \mid$ Representative colony size of mild fibromatoses cells transfected with $\operatorname{jun} B(a), \mathrm{c}-j u n(b)$, or $j u n D(c)$ or untransfected mild fibromatosis cells $(d)$. Magnification, $81 \times$.

PDGF receptor by the BPV5 E5 oncoprotein (Petti et al. 1991), which in turn could signal up-regulation of c-jun and $j u n B$, as has been observed in other systems with serum and PDGF (Quantin and Breathnach 1988; Ryder and Nathans 1988; Ryder et al. 1988). Additional factors could be the observed mutation of the p53 tumor suppressor gene, (E. B.-Wetzel and D. Hanahan, unpubl.) or release of basic fibroblast growth factor (bFGF) (Kandel et al. 1991) a potential autocrine growth factor. It is notable that the up-regulation of $j u n B$ and c-jun typically does not appear to be focal or sectoral but, rather, seems uniform in the aggressive fibromatosis and fibrosarcoma tissue. The pattern might indicate involvement of a diffusible factor in the activation of junB and c-jun.

\section{Transformation and transcriptional activation by Jun proteins}

Members of the iun and fos family have been implicated previously in cellular transformation, either by mutational alterations of the coding sequence or by increased expression of otherwise normal Jun or Fos gene products (for review, see Vogt and Tjian 1988; Herrlich and Ponta 1989; Vogt and Bos 1990; Angel and Karin 1991; Lewin 1991). c-jun was identified by homology to v-jun, the oncogene captured in an avian sarcoma virus (ASV17) (Maki et al. 1987). Transgenic mice carrying the v-jun oncogene under control of the widely expressed $\mathrm{H}-2 \mathrm{~K}^{\mathrm{k}}$ major histocompatibility complex promoter develop dermal fibrosarcomas and rhabdomyosarcomas, but only after skin wounding (Schuh et al. 1990). The v-jun fibrosarcoma phenotype is similar to that of BPV-1 transgenic mice, where tumors also tend to arise in areas of skin irritation or wounding. In BPV-1 transgenic mice, how- ever, wounding does not appear to be a strict prerequisite nor is it sufficient for the induction of neoplasia.

There is precedent for participation of cellular jun and fos proto-oncogenes in transformation, and previous studies have suggested that changes in the relative abundance of Jun/Fos proteins might be influential (Schütte et al. 1989a,b; Castellazzi et al. 1990 1991). The experiments described in this report have demonstrated that AP-1 DNA-binding activity is increased significantly in fibrosarcomas when compared with normal skin fibroblast nuclear extracts. The Fos levels are high in all four stages, whereas JunB and c-Jun levels rise in the latter two stages, concomitant with increased AP-1-binding activity. The supershift experiment with anti-Fos antibodies indicates that a substantial fraction of the new AP-1 activity is in the form of Jun/Fos heterodimers, because Fos proteins cannot bind DNA. Yet it appears that the levels of JunB and c-Jun are rising to exceed those of Fos not only to produce Jun/Fos heterodimers but also c-Jun and JunB homo- and heterodimers, which might have functionally distinct activity or specificity from that of Jun/Fos heterodimers. This suggestion is consistent with other observations of differential activity between Jun/Fos and Jun/Jun dimers (Halazonetis et al. 1988; Nakabeppu et al. 1988; Schütte et al. 1989b; Diamond et al. 1990; Doucas et al. 1991; Ryseck and Bravo 1991). It is also intriguing that the levels of JunD appear to decrease in the fibrosarcomas, suggesting that JunD might antagonize or be down-regulated by JunB and c-Jun.

Jun genes as cooperating oncogenes and a secondary event

To address the functional significance of JunB and c-Jun 
up-regulation in this tumorigenesis pathway, normal fibroblasts and mild fibromatosis cells were transfected with the cDNAs of the three different jun genes. Overexpression of c-jun and, to a lesser degree, junB, conferred on mild fibromatosis cells the ability to grow in soft agar, a phenotype characteristic of aggressive fibromatosis and fibrosarcoma cells that probably represents the anchorage independence of invasive tumor cells. In contrast, junD transfections did not allow mild fibromatosis cells to grow in soft agar. The cell phenotype of normal fibroblasts was unaffected by any of the iun transfections. One possible explanation for the lack of effect on the normal cell type lies in the expression of the BPV-1 oncoproteins. The BPV-1 oncoproteins E5 and E6 are not expressed in fibroblasts obtained from normal transgenic skin but are expressed at low levels in mild fibromatoses cells. It is therefore conceivable that BPVI E5 and/or E6 proteins can cooperate with JunB or c-Jun in transformation and, moreover, that their actions must precede those of the Jun proteins, which are only effective upon already aberrantly proliferating cells. The inability of c-jun to transform normal dermal fibroblasts is consistent with the lack of a tumorigenic phenotype when c-jun is overexpressed in a variety of tissues in transgenic mice, including dermal fibroblasts (F. Hilberg and E.F. Wagner, pers. comm.).

It is of note that several key properties of the fibrosarcomas were missing in both junB- and c-jun-transfected mild fibromatosis cells. Fibrosarcoma cells are small spindle-shaped cells that grow in a crisscross pattern; they are not contact inhibited, and they rapidly form tumors upon transplantation into nude or histocompatible mice. None of these qualities was observed in iun-transfected mild fibromatosis cells. Thus, up-regulation of JunB and c-Jun appears to evoke functions that are related to anchorage independence and consequent growth in soft agar but is not sufficient for the complete tumor cell phenotype. It is conceivable that several independent genetic and/or epigenetic alterations may play distinct roles in the progression to fibrosarcomas. Recent studies of this transgenic mouse model have indicated that the increases in JunB and c-Jun are not the only changes occurring during fibrosarcoma formation. The localization of bFGF, a growth factor with angiogenic properties, is changed from its normal cell-associated state and is instead exported in aggressive fibromatosis and fibrosarcoma cells (Kandel et al. 1991). The export of bFGF is likely to be responsible for the neovascularization and rapid expansion of both aggressive fibromatosis and fibrosarcomas in vivo. Our preliminary analysis suggests that in jun-transfected mild fibromatosis cells, the localization of bFGF was not altered from its normal, cell-associated state to the exported form (J. Kandel and E. B.-Wetzel, unpubl.). This result suggests that export of bFGF and the coactivation of c-Jun and JunB are independent events and contribute to different characteristics of fibrosarcoma cells. The failure of jun overexpression to induce export of bFGF may also explain the inability of Jun-transfected mild fibromatosis cells to form tumors upon transplantation into nude mice.

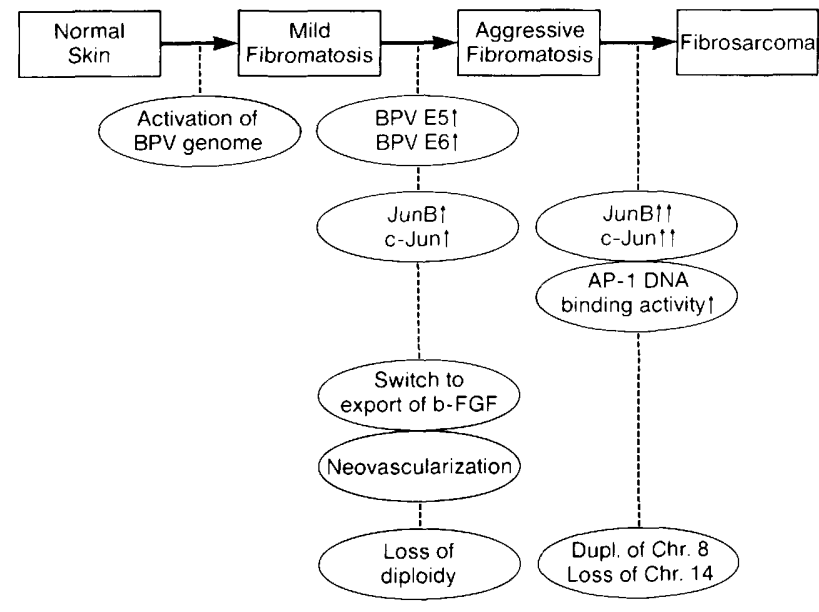

Figure 7. A model of dermal fibrosarcoma development. The boxes represent the normal condition and the three histologically distinct stages. The ovals represent stage-specific changes that are clearly implicated in this tumorigenesis pathway.

A schematic depiction of the known stage-specific changes accompanying fibrosarcoma development is shown in Figure 7. The first step involves transcriptional activation of the latent BPV-1 genome, producing the mild fibromatosis stage. The next stage, aggressive fibromatosis, is characterized by several changes that may occur independently and represent intermediate substages. Expression of the BPV-1 genome and the E5 and E6 oncoproteins increases. The levels of JunB and c-Jun are elevated, as is the associated DNA-binding activity for the APl site. The release of the growth factor, bFGF, is observed, correlating with neovascularization of aggressive fibromatosis tissue in vivo. In the fibrosarcoma stage, duplication of chromosome 8 and/or loss of chromosome 14 is observed. The levels of c-Jun and JunB are increased further, and there is an additional increase in AP-1 DNA-binding activity. The functional analysis presented herein suggests that up-regulation of $j u n B / \mathrm{c}-j u n$ induces a component of the malignant phenotype. Because these proto-oncogenes encode gene regulatory factors, it is evident that there should now be a focus on identifying the target genes being affected by JunB/c-Jun, as well as on the mechanisms of jun up-regulation, to understand more completely their roles as progression factors during this multistep tumorigenesis process. Finally, it will be of interest to examine the expression and possible involvement of $j u n B$ and c-jun in human fibrosarcomas and other mesenchymal tumors.

\section{Materials and methods}

\section{Transgenic mice}

Generation of BPV1.69 and BPV.69rI transgenic mice and their tumor phenotype has been described previously (Lacey et al. 1986; Lindgren et al. 1989|.

\section{Antiserum}

Characterization of JunB-, c-Jun-, and JunD-specific antibodies used for immunohistochemistry and Western blot analysis has 
been described (Kovary and Bravo 1991). Each selectively recognizes only the protein toward which it was generated, and not the other related Jun proteins. The anti-c-Fos antibodies used for immunohistochemistry and the gel retardation experiment were a gift of R. Franza (Cold Spring Harbor Laboratory). The anti-c-Fos antibodies used in Western blot analysis, a gift from M. Nicklin and E.F. Wagner (I.M.P., Vienna, Austria), were generated against a amino-terminal peptide /sequence SGFNADYEASS-RC) and affinity purified by passage over a peptide column. The anti-c-Jun antibodies (AB-1 and AB-2) used for immunohistochemistry were purchased from Oncogene Sciences. Additional anti-c-Jun antibodies used for confirmatory Western blot analysis were a gift from C. Pfarr, G. Spyrou, and M. Yaniv (Institute Pasteur, Paris, France). Anti-c-Myc antibodies were a gift from G. Ramsay and J.M. Bishop (University of California, San Francisco).

\section{Cell cultures}

Cell cultures were established either from BPV1.69 or BPV.69rI transgenic mice. Skin or tumor tissue was minced into small pieces with a scissors and incubated in $0.1 \%$ Dispase and $0.02 \%$ collagenase in PBS at $37^{\circ} \mathrm{C}$ under continuous agitation for 45 min. The cells were plated in Dulbecco's modified Eagle medium (DMEM) plus $5 \%$ bovine calf serum containing penicillin and streptomycin. Normal skin fibroblast and mild fibromatosis cultures were routinely seeded at $1 \times 10^{5}$ cells $/ 100-\mathrm{mm}$ dish and maintained for $<20$ passages. The derivation of immortal aggressive fibromatosis and fibrosarcoma cells has been described previously (Sippola-Thiele et al. 1989). These cells were maintained much as the normal fibroblasts and mild fibromatosis cultures.

\section{Expression vectors}

The complete coding regions of mouse c-jun, jun $B$, and junD were cloned into the mammalian expression vector pMexneo, which utilizes a MSV-LTR and a polyadenylation signal of SV40 (Martin-Zanca et al. 1989). The constructs were confirmed by sequencing.

\section{Immunohistochemistry}

Skin or tumor tissue was infiltrated in a solution of $15 \%$ sucrose and PBS at $4^{\circ} \mathrm{C}$ overnight. Unfixed tissue was then mounted in tissue Tek OCT embedding medium on a dry ice block. Tissue was sectioned at $10 \mu \mathrm{m}$ using a cryostat microtome at $-30^{\circ} \mathrm{C}$, and sections were collected on Superfrost/plus microscope glass slides (Fisher) and air-dried at room temperature for $1 \mathrm{hr}$. For immunostaining, sections were rehydrated in PBS for $10 \mathrm{~min}$ and permeabilized in $0.25 \% \mathrm{NP}-40$ and $\mathrm{PBS}$ for $15 \mathrm{~min}$. The sections were then washed three times for $5 \mathrm{~min}$ each in PBS and treated with blocking solution [ $3 \%$ goat serum, $3 \%$ bovine serum albumin, $3 \%$ fetal bovine serum (FBS)] for $30 \mathrm{~min}$ and incubated with the primary antibody. Each antiserum was titrated on cryosections of BPV1.69 skin and fibrosarcoma tissue. Dilutions of $1: 500,1: 800,1: 1000,1: 2000$, and $1: 10,000$ were tested. Antibodies were diluted in binding buffer (DMEM, $10 \%$ FBS, 50 mM HEPES at $\mathrm{pH} 7.4$ ) and incubated with sections for $4 \mathrm{hr}$ or overnight at room temperature. The sections were washed three times with PBS plus $3 \%$ goat serum for 5 min each, and a $1: 200$ dilution of peroxidase-conjugated goat antirabbit IgG secondary antibodies was applied (Accurate Chemical and Scientific Corp.) for $1 \mathrm{hr}$ at room temperature. After several wash steps with PBS plus $1 \%$ goat serum, the immunocomplexes were visualized by treatment with a solution of 0.25 $\mathrm{mg} / \mathrm{ml}$ of diaminobenzidine, $3 \mathrm{mg} / \mathrm{ml}$ of nickel sulfate, and
$0.003 \% \mathrm{H}_{2} \mathrm{O}_{2}$. The substrate reaction was stopped after $6-8 \mathrm{~min}$ by washing the sections in $\mathrm{H}_{2} \mathrm{O}$. Slides were then taken through graded alcohol into xylene and mounted with coverslips using Entellan mounting compound. The sections were evaluated on a Nikon Microphot-FX microscope, and photographs were taken using Kodak Technical Pan film (ASA 25).

\section{Transfections}

Transfections were performed using the calcium phosphate DNA coprecipitation method. Low-passage normal fibroblast or mild fibromatosis cells from BPV-1 transgenic mice were seeded at a density of $1 \times 10^{6}$ cells $/ 10-\mathrm{cm}$ culture dish in DMEM plus $10 \%$ FBS and grown overnight. Ten micrograms of pMexneo, pMexneo-junB, pMexneo-c-jun, or pMexneo-junD was used for transfection of each $10-\mathrm{cm}$ dish. Forty-eight hours after transfection, each plate of cells was trypsinized and reseeded into four $10-\mathrm{cm}$ culture dishes containing G4l $(500 \mu \mathrm{g} / \mathrm{ml}$, GIBCO|. On average, 30 independent G418-resistant clones for each transfection type were isolated 2-3 weeks later and expanded into cell lines.

\section{Colony-forming assay in soft agar}

Cells $\left(1 \times 10^{5}\right.$ or $\left.1 \times 10^{4}\right)$ were mixed with $3 \mathrm{ml}$ of $0.36 \%$ Difco agar containing DMEM plus $5 \%$ bovine calf serum and plated in triplicates into $60-\mathrm{mm}$ culture dishes on top of $3 \mathrm{ml}$ of $0.72 \%$ hard agar layer. The cells were refed with an additional $3 \mathrm{ml}$ of soft agar medium after 1 and 2 weeks of incubation. After 3 weeks, the colonies were stained with $200 \mu \mathrm{l}$ per dish of $5 \mathrm{mg}$ / $\mathrm{ml}$ 3-(4,5-dimethylthiazol-zyl)-2-5-diphenyl tetrazolium bromide (MTT) (Sigma) in PBS for 4-6 hr, and colonies were counted.

\section{Tumorigenicity assay}

Tumorigenicity was tested by injecting the abdominal region of Scid, B6D2F1, or athymic mice subcutaneously with $2 \times 10^{6}$, $1 \times 10^{5}$ or $1 \times 10^{5}$ cells in $0.5 \mathrm{ml}$ of DMEM per animal. The mice were scored weekly for tumor formation and volume for 3 months.

\section{Preparation of nuclear extracts}

Large-scale nuclear extracts were prepared as described in Piette et al. (1988). These extracts were used for the Western blotting analyses shown in Figure 2. Alternatively, when multiple cell lines were being compared in gel-shift assays or Western blotting analyses of jun-transfected mild fibromatosis cells, a microscale nuclear extract was prepared according to the technique described by Andrews and Faller (1991).

\section{Western blot analysis}

The protein concentration of the nuclear extracts was determined using the Bio-Rad Protein Determination Assay. Twenty micrograms of protein was loaded into each lane of a $10 \%$ SDSpolyacrylamide gel. After electrophoresis at $45 \mathrm{~V}$ overnight, the gel was equilibrated in transfer buffer $(20 \mathrm{~mm}$ Tris, $150 \mathrm{~mm}$ glycine, $20 \%$ methanol) for $30 \mathrm{~min}$, and proteins were transferred to Hybond-ECL nitrocellulose $(0.45 \mu \mathrm{m})$ (Amersham) for $2 \mathrm{hr}$ at $150 \mathrm{~V}$ and $4^{\circ} \mathrm{C}$. After transfer, the nitrocellulose filter was treated to prevent nonspecific binding with blocking solution $3 \%$ nonfat milk powder, $3 \%$ BSA, $0.1 \%$ Tween 20 in PBS) for $1 \mathrm{hr}$ at room temperature. The primary antibodies were diluted in PBS, 3\% nonfat milk powder, and $0.1 \%$ Tween 20 (JunB antiserum, $1: 800$; c-Fos IgGs, $1 \mu \mathrm{g} / \mathrm{ml}$; JunD antiserum, 
$1: 1000$; c-Jun antiserum, $1: 800$ and incubated for $1 \mathrm{hr}$ at room temperature under constant agitation. The filter was then washed four times for 5 min each, with PBS, 3\% nonfat milk, and $0.1 \%$ Tween 20 . The second antibody, a goat anti-rabbit horseradish peroxidase (HRP) (Accurate) was incubated at a $1: 50,000$ or $1: 25,000$ dilution in blocking solution for $30 \mathrm{~min}$ to $1 \mathrm{hr}$. The filter was then washed extensively (four times, for 5 min each) with PBS, $3 \%$ nonfat milk, and $0.1 \%$ Tween 20 and then twice with PBS only. To detect the immunocomplexes, the ECL-Western blotting detection system (Amersham) was used according to the instructions of the manufacturer. The nitrocellulose filter was then exposed to XAR-5 Kodak X-ray film for periods ranging from $10 \mathrm{sec}$ to a maximum of $2 \mathrm{~min}$.

\section{Gel-retardation experiment}

Five micrograms of protein from the microscale nuclear extraction (Andrews and Faller 1991) was incubated on ice for $15 \mathrm{~min}$ with $1 \mu \mathrm{g}$ of poly[d(I-C)]/poly[(I-C)] in binding buffer $(20 \mathrm{mM}$ Tris at $\mathrm{pH} 7.9,1 \mathrm{~mm}$ EDTA, $0.1 \%$ NP-40, $1 \mathrm{~mm}$ DTT, $6.25 \%$ Ficoll) and $0.1 \mu \mathrm{g} / \mu \mathrm{l}$ of BSA in a final reaction volume of $25 \mu \mathrm{l}$. Then $20,000 \mathrm{cpm}(0.1 \mathrm{ng})$ of ${ }^{32} \mathrm{P}$-end-labeled double-stranded oligonucleotide containing the AP-1 consensus sequence $5^{\prime}$ CTAGACTGAACGGTGACTCAAACTGCCGCTGCA-3' was added to each reaction and incubated for an additional 15-30 min at room temperature. The reaction mixture was loaded immediately on a $6 \%, 0.5 \times \mathrm{TBE}$ polyacrylamide gel and run at $250 \mathrm{~V}$ in $0.5 \times \mathrm{TBE}$ buffer at $4^{\circ} \mathrm{C}$ for $1.5-2 \mathrm{hr}$. The gel was subsequently fixed (10\% acetic acid, $20 \%$ methanol), dried, and exposed overnight to Kodak XAR-5 X-ray film. To test specificity of DNA binding a 100-fold molar excess of unlabeled mutant oligonucleotide (5'-AATAGAATTCGATTAATTATTGATATTGAAA-3') or a 100-fold molar excess of the AP-1-specific oligonucleotide was added to the reaction before adding the radiolabeled probe. If Jun- or Fos-specific antibodies were added to the reaction, nuclear extract and antibodies were preincubated for $1 \mathrm{hr}$ in binding buffer on ice. Then ${ }^{32} \mathrm{P}$-labeled oligonucleotide containing the AP-1 consensus sequence was added and incubated for an additional $20 \mathrm{~min}$ at room temperature.

\section{Acknowledgments}

We thank the following people for their efforts: Lena DiLacio, Anne Neill, and Sarah Lennox for expert technical assistance; Keith Yamamoto, Erwin Wagner, and Peter Howley for helpful suggestions and critical reading of the manuscript; Karla Kovary for gifts of c-Jun-, JunB-, and JunD-specific antibodies; Curt Pfarr and Moshe Yaniv for providing their c-Jun-, JunB,- and JunD-specific antibodies; Robert Franza, Erwin Wagner, and Martin Nicklin for their Fos-specific antibodies; Jeff Miner, Keith Yamamoto, and Michael Blanar for oligonucleotides containing the AP-1 consensus sequence and technical advice on the gel mobility assay. We are also grateful to Lou Reichardt for use of photographic facilities, and we thank Peter Howley for advice and encouragement throughout this project. Finally, we thank Leslie Spector for preparing the manuscript. This research was supported by a grant from the National Cancer Institute and benefited from core support for equipment and animal facilities provided by the Lucille Markey Charitable Trust. The publication costs of this article were defrayed in part by payment of page charges. This article must therefore be hereby marked "advertisement" in accordance with 18 USC section 1734 solely to indicate this fact.

\section{References}

Aaronson, S.A. 1991. Growth factors and cancer. Science 254: $1146-1153$.
Andrews, N.C. and D.V. Faller. 1991. A rapid micropreparation technique for extraction of DNA binding proteins from limiting numbers of mammalian cells. Nucleic Acids Res. 19: 2499 .

Angel, P. and M. Karin. 1991. The role of Jun, Fos and the AP-1 complex in cell proliferation and transformation. Biochim. Biophys. Acta 1072: 129-157.

Angel, P., E.A. Allegretto, S.T. Okino, K. Hattari, W.J. Boyle, T. Hunter, and M. Karin. 1988. Oncogene jun encodes a sequence specific transactivator similar to AP-1. Nature 332: 166-171.

Bishop, J.M. 1991. Molecular themes in oncogenesis. Cell 64: 235-248.

Bohmann, D. and R. Tjian. 1989. Biochemical analysis of transcriptional activation by Jun: Differential activity of c- and v-Jun. Cell 59: 709-717.

Bohmann, D., T.J. Bos, A. Admon, T. Nishimura, P. Vogt, and R. Tjian. 1987. Human proto-oncogene $c$-jun encodes a DNA binding protein with structural and functional properties of transcription factor AP-1. Science 238: 1386-1392.

Bos, T.J., F.S. Monteclaro, F. Mitsunobu, A.R.J. Ball, C.H.W. Chung, T. Nishimura, and P.K. Vogt. 1990. Efficient transformation of embryo fibroblasts by c-jun requires structural modification in coding and noncoding sequences. Genes \& Dev. 4: $1677-1687$.

Castellazzi, M., J.-P. Dangy, F. Mechta, S.-I. Hirai, M. Yaniv, J. Samarut, A. Lasschilly, and G. Brun. 1990. Overexpression of avian or mouse cjun in primary chick embryo fibroblasts confers a partially transformed phenotype. Oncogene 5: 1541-1547.

Castellazzi, M., G. Spyrou, N. La Vista, J.-P. Dangy, F. Piu, M. Yaniv, and G. Brun. 1991. Overexpression of c-jun, junB or junD affects cell growth differently. Proc. Natl. Acad. Sci. 88: 8890-8894.

Cohen, R.D. and T. Curran. 1988. fra-1: A serum inducible, cellular immediate-early gene that encodes a Fos-related antigen. Mol. Cell Biol. 8: 2063-2069.

Diamond, M.I., J.N. Miner, S.K. Yoshinaga, and K.R. Yamamoto. 1990. Transcriptional factor interaction: Selective or negative regulation from a single DNA element. Science 249: 1266-1272.

Doucas, V., G. Spyrou, and M. Yaniv. 1991. Unregulated expression of c-Jun or c-Fos proteins but not JunD inhibits oestrogen receptor activity in human breast cancer derived cells. EMBO I. 10: 2237-2245.

Fearon, E.P. and B. Vogelstein. 1990. A genetic model for colorectal tumorigenesis (review). Cell 61: 759-767.

Garcia, M. and J. Samarut. 1990. Cooperation of v-jun and $\mathrm{v}$-erbB oncogenes in embryo fibroblast transformation in vitro and in vivo. J. Virol. 64: 4684-4690.

Garcia-Carranca, A., F. Thierry, and M. Yaniv. 1988. Interplay of viral and cellular proteins along the long control region of human papillomavirus 18. J. Virol. 63: 4321-4330.

Halazonetis, T.D., K. Georgopoulos, M.E. Greenberg, and P. Leder. 1988. c-Jun dimerizes with itself and with c-Fos forming complexes of different DNA binding affinities. Cell 55: 917924.

Herrlich, P. and H. Ponta. 1989. Nuclear oncogenes convert extracellular stimuli into changes in the genetic program. Trends Genet. 5: 112-116.

Hirai, S.-I., R.-P. Ryseck, F. Mechta, R. Bravo, and M. Yaniv. 1989. Characterization of JunD: A new member of the jun proto-oncogene family. $E M B O$ J. 8: 1433-1439.

Kandel, J., E. Bossy-Wetzel, F. Radvanyi, M. Klagsbrun, J. Folkman, and D. Hanahan. 1991. Neovascularization is associated with a switch to the export of bFGF in the multistep 
development of fibrosarcoma. Cell 66: 1095-1104.

Kovary, K. and R. Bravo. 1991. Expression of different Jun and Fos proteins during the G0 to Gl transition in mouse fibroblasts: In vitro and in vivo association. Mol. Cell. Biol. 11: 2451-2459.

Lacey, M., S. Alpert, and D. Hanahan. 1986. Bovine papillomavirus genome elicits skin tumours in transgenic mice. $\mathrm{Na}$ ture 322: 609-612.

Lewin, B. 1991. Oncogenic conversion by regulatory changes in transcription factors. Cell 64: 303-312.

Lindgren, V., M. Sippola-Thiele, J. Skowronski, E. Wetzel, P.M. Howley, and D. Hanahan. 1989. Specific chromosomal abnormalities characterize fibrosarcomas of bovine papillomavirus type 1 transgenic mice. Proc. Natl. Acad. Sci. 86: 5025-5029.

Maki, Y., T. Bos, C. Davis, M. Starbuck, and P. Vogt. 1987. Avian sarcoma virus 17 carries the jun oncogene. Proc. Natl. Acad. Sci. 84: 2848-2852.

Martin, M.E., J. Piette, M. Yaniv, and W.R. Folk. 1988. Activation of the polyoma-virus enhancer by murine AP-1 homolog and two contiguous proteins. Proc. Natl. Acad. Sci. 85: 5839-5843.

Martin-Zanca, D., R. Oskam, G. Mitra, T. Copeland, and M. Barbacid. 1989. Molecular and biochemical characterization of the human trk-proto-oncogene. Mol. Cell. Biol. 9: 24-33.

Mattei, M.G., D. Simon-Chazottes, S.-I. Hirai, R.-P. Ryseck, Z. Galcheva-Gargova, J.-L. Guenet, J.F. Mattei, R. Bravo, and M. Yaniv. 1990. Chromosomal localization of the three members of the jun proto-oncogene family in mouse and man. Oncogene 5: 151-156.

Nakabeppu, Y., K. Ryder, and D. Nathans. 1988. DNA binding activities of three murine Jun proteins: Stimulation by Fos. Cell 55: 907-915.

Petti, L., L.A. Nilson, and D. DiMaio. 1991 Activation of the platelet-derived growth factor receptor by the bovine papillomavirus E5 transforming protein. EMBO J. 10: 845-855.

Piette, J., S.-I. Hirai, and M. Yaniv. 1988. Constitutive synthesis of activated protein 1 transcription factor after viral transformation of mouse fibroblasts. Proc. Natl. Acad. Sci. 85: 3401-3405.

Quantin, B. and R. Breathnach. 1988. Epidermal growth factor stimulates transcription of the c-jun proto-oncogene in rat fibroblasts. Nature 334: 538-539.

Rauscher, F.J.I., L.C. Sambucetti, T. Curran, R.J. Distel, and B.M. Spiegelman. 1988a. Common DNA binding site for Fos protein complexes and transcription factor AP-1. Cell 52: $471-480$.

Rauscher, F.J.I., P.J. Voulalas, B.R. Franza, Jr., and T. Curran. 1988b. Fos and Jun bind cooperatively to the AP-1 site: Reconstitution in vitro. Genes \& Dev. 2: 1687-1699.

Ryder, K., A. Lanahan, E. Perez-Albuerne, and D. Nathans. 1989. JunD: A third member of the Jun gene family. Proc. Natl. Acad. Sci. 86: 1500-1503.

Ryder, K. and D. Nathans. 1988. Induction of protooncogene c-jun by serum growth factors. Proc. Natl. Acad. Sci. 85: 8464-8467.

Ryder, K., L. Lau, and D. Nathans. 1988. A gene activated by growth factors is related to the oncogene v-jun. Proc. Natl. Acad. Sci. 85: 1487-1491.

Ryseck, R.-P. and R. Bravo. 1991. cJun, JunB and JunD differ in their binding affinity to AP1 and CRE consensus sequence: Effect of Fos proteins. Oncogene 6: 533-542.

Ryseck, R.-P., S.I. Hirai, M. Yaniv, and R. Bravo. 1988. Transcriptional activation of c-jun during the $\mathrm{G}_{0} / \mathrm{G}_{1}$ transition in mouse fibroblasts. Nature 334: 535-537.

Schönthal, A., P. Herrlich, H.J. Ramsdorf, and H. Ponta. 1988.
Requirement for fos gene expression in the transcriptional activation of collagenase by other oncogenes and phorbol ester. Cell 54: 325-334.

Schuh, A.C., S.J. Keating, F.S. Monteclaro, P.K. Vogt, and M.L. Breitman. 1990. Obligatory wounding requirement for tumorigenesis in v-jun transgenic mice. Nature 346: 756-760.

Schütte, J., J.D. Minna, and M.J. Birrer. 1989a. Deregulated expression of human c-jun transforms primary rat embryo cells in cooperation with an activated c-Ha-ras gene and transforms Rat-1a cells as a single gene. Proc. Natl. Acad. Sci. 86: $2257-2261$.

Schütte, J., J. Viallet, M. Nau, S. Segal, J. Fedorko, and J. Minna. $1989 \mathrm{~b}$. junB inhibits and c-fos stimulates the transforming and trans-activating activities of c-jun. Cell 59: 987-997.

Sippola-Thiele, M., D. Hanahan, and P.M. Howley. 1989. Cellheritable stages of tumor progression in transgenic mice harboring the bovine papillomavirus type 1 genome. Mol. Cell. Biol. 9: 925-934.

Solomon, E., J. Borrow, and A.D. Goddard. 1991. Chromosome aberrations and cancer. Science 254: 1153-1160.

Vogt, P.K.V. and T.J. Bos. 1990. Jun: Oncogenes and transcription factor. Adv. Cancer Res. 55: 1-35.

Vogt, P. and R. Tjian. 1988. Minireview Jun: A transcriptional regulator turned oncogenic. Oncogene 3: 3-7.

Weinberg, R. 1991. Tumor suppressor genes. Science 254: 1138 1145.

Wilkinson, D.G., S. Bhatt, R.-P. Ryseck, and R. Bravo 1989. Tissue-specific expression of c-jun and junB during organogenesis in the mouse. Development 106: 465-471.

Zerial, M., L. Toschi, R.-P Ryseck, M. Schurmann, R. Muller, and R. Bravo. 1989. The product of a novel growth factor activated gene, fosB, interacts with Jun proteins enhancing their DNA binding activity. EMBO I. 8: 805-813. 


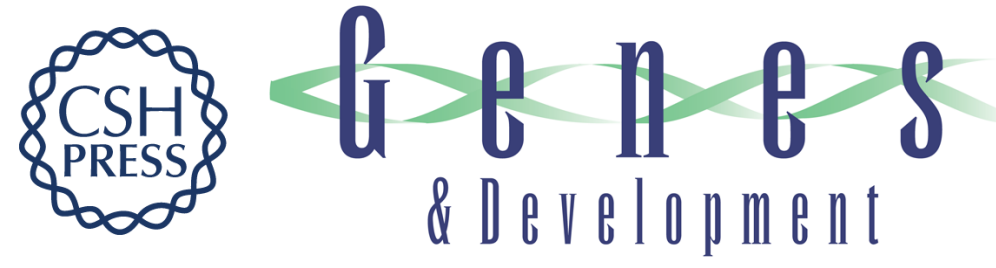

\section{Transcription factors junB and c-jun are selectively up-regulated and functionally implicated in fibrosarcoma development.}

E Bossy-Wetzel, R Bravo and D Hanahan

Genes Dev. 1992, 6:

Access the most recent version at doi:10.1101/gad.6.12a.2340

References This article cites 50 articles, 21 of which can be accessed free at:

http://genesdev.cshlp.org/content/6/12a/2340.full.html\#ref-list-1

License

Email Alerting

Service

Receive free email alerts when new articles cite this article - sign up in the box at the top right corner of the article or click here.

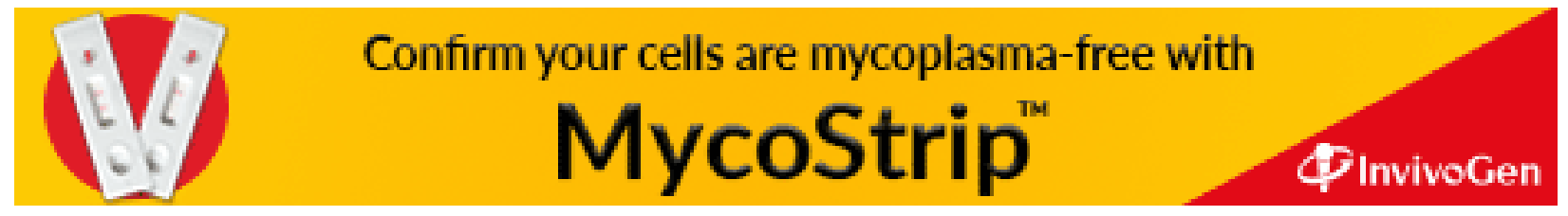

